\title{
Factors Affecting Decision Making Process on Spine Surgery: Patients' Perspective
}

\author{
FAZAL GHANI ${ }^{1}$, IRUM KHATTAK ${ }^{2}$, SHABNUM AAMIR ${ }^{3}$, FAROOQ AZAM ${ }^{4}$ \\ ${ }^{1}$ Department of Neurosurgery, Khyber Teaching Hospital, ${ }^{2}$ Department of Management Sciences, \\ Islamia College, ${ }^{3}$ Department of Anatomy, Khyber Medical College \\ ${ }^{4}$ Department of Neurosurgery, Lady Reading Hospital, Peshawar-Pakistan \\ DOI 10.36552/pjns.v24i2.445
}

\begin{abstract}
Objective: To determine the factors that affects the decision making process of the spine surgery from a patient's perspective.

Material and Methods: The study was carried on 264 patients admitted for spine surgery in the Department of Neurosurgery, Khyber Teaching Hospital, Peshawar, Pakistan. Data was collected from patients on questionnaire using a Likert scale. Reliability was ensured by Cronbach alpha.

Results: The results for regression analysis revealed that there is a significant negative relationship between previous experiences and decision for spine surgery in patients $(\beta=-0.156, p=0.001<0.05)$. There is a significant positive influence of emotional and social state $(\beta=0.193, p=0.002)$, information $\&$ counselling $(\beta=$ 0.097, $p=0.011)$, socioeconomic status $(\beta=0.131, p=0.004)$, severity of disability $(\beta=0.602, p=0.000)$, ineffective conservative treatment $(\beta 9=0.082, p=0.013)$ and intensity of pain $(\beta=0.527, p=0.000)$ on decision for spine surgery in patients. The independent variables, including physical health, gender role and age were found to have an insignificant effect on the decision for spine surgery $(p>0.05)$.

Conclusion: It is concluded that the factors affecting the decision of patients on spine surgery included previous experience, emotional \& social state, information \& counselling, socioeconomic status, severity of disability, ineffectiveness of previously taken conservative treatment and intensity of pain.
\end{abstract}

Keywords: Spine surgery, Factors, Pain, Health, Disability, Conservative, Emotional State.

\section{INTRODUCTION}

Spine disorder is one of the major health problems in industrialized countries. ${ }^{1}$ It is not only confined to developed nations, but there is also a rising trend of backache or lower limb problems in developing countries. Due to globalization, the changing lifestyle needs more attention regarding health problems around theglobe.

Patients having spine disorders experience back or lower limb pain, leading to problems in walking or even chronic stages such as disability if it is not treated earlier. ${ }^{1,2}$ Conservative treatments is opted in first place for spine disorders. It includes physical therapy, pharmacological treatment and epidural injection. ${ }^{2}$
Recent studies suggested that surgical method is more useful when it is done in early times as compared to conservative or non-surgical treatment. ${ }^{1,2}$ Despite the fact that surgical intervention is more appropriate in certain instances, patients seem reluctant to go under spine surgery due to their reservations and perception that the spine surgery could lead to disability or death.

Previous studies identified various factors that have a considerable influence over the decision of spine surgery from a patient's perspective.Personal characteristics such as age, work status and gender were found to have an association with a preference for spine surgery decision., ${ }^{4,6}$ Another important factor is intensity of pain which has a strong impact on 
decision of spine surgery. ${ }^{4,5}$ Physical health was another factor reported in studies that can influence the decision on spine surgery for patients ${ }^{2}$. Severe disability and difficulty in walking tend towards the decision for spine surgery. ${ }^{4,6}$ Emotional and social state that result from negative feelings from the longlasting symptoms and pain in patients influence their choice for surgery. ${ }^{2,4}$ Patient decision regarding spine surgery is affected by effectiveness of conservative treatment, if it brings no change in their condition; it entails a high preference for surgical operation. ${ }^{2}$ Information and counselling from medical professional affect decision of patient for spinal surgery. ${ }^{2,3}$ Previous Experiences such as those of close relatives greatly influence the decision of a patient for opting spine surgery. ${ }^{3}$

According to the shared decision-making (SDM) model, it is recommended that the clinician and patient should together come to a conclusion regarding surgery. For the best treatment of a patient, it is necessary that clinician share their expertise and knowledge with patient taking decision for surgery. ${ }^{3}$ Therefore, it is utmost important for neurosurgeons to understand factors that influence the decision of patient on spine surgery. Furthermore, studies related to factors that affect the decision making process of spine surgery are mainly related to developed countries and little attempt has been made to identify such factors in developing country like Pakistan. This study aims to identify factors from the patients' perspective that can influence spinal surgery decision that can have useful implications for clinicians to counsel patients and achieve the goals of the shared decision model in the field of neurosurgery and make a contribution to the literature from developing countries' perspective.

\section{MATERIALS AND METHODS}

\section{Study Setting}

The data for the study was collected from Department of Neurosurgery, Khyber Teaching Hospital Peshawar, Pakistan. All patients were first seen in OPD by a group of neurosurgeons. The study design is quantitative in nature. Data was collected from patients on the questionnaire and filled by the researcher on the spot to facilitate the respondent in understanding questionnaireand due to the low rate of literacy in the country.

\section{Inclusion Criteria}

All the respondents had MRI verified lumbar disc herniation with concordant symptoms and were prescribed spine surgery. The consents of patients were taken for survey. All patients that choose surgery were remained the part of the study and were admitted for spine surgery in Department of Neurosurgery, Khyber Teaching Hospital Peshawar, Pakistan. The sample of the study consists of 264 patients.

\section{Exclusion Criteria}

Who did not gave current 80 patients with comorbidities were excluded.

\section{Data Collection}

A structured questionnaire using a Likert scale was used in the study and checked by the expert in the field of quantitative research and medical professionals for face validity and content validity. Reliability of the instrument was ensured through the Cronbach alpha test.

\section{Data Analysis}

Descriptive statistics (mean) and inferential statistics were used for data analysis. Hypothesis testing was performed through multiple regression analysis. Correlation analysis was also performed.

\section{RESULTS}

The results for descriptive statistics for variables including minimum, maximum, mean and standard deviation based on patient'sresponses are given in Table 1. Severity of disability has the highest mean

Table 1: Descriptive Statistics $(n=264)$.

\begin{tabular}{|l|c|c|c|c|c|}
\hline & N & Minimum & Maximum & Mean & Standard Deviation \\
\hline Previous experience & 264 & 1.67 & 5.00 & 4.0556 & .57723 \\
\hline Emotional \& social state & 264 & 2.00 & 5.00 & 4.0795 & .49755 \\
\hline Information \& counselling & 264 & 2.67 & 5.00 & 4.0455 & .42972 \\
\hline
\end{tabular}


Fazal Ghani, et al

\begin{tabular}{|l|l|l|l|l|c|}
\hline Socioeconomic status & 264 & 2.00 & 5.00 & 4.0404 & 4.0972 \\
\hline Severity of disability & 264 & 1.67 & 5.00 & 4.0250 & .50604 \\
\hline Physical health & 264 & 1.93 & 4.73 & 3.9066 & .70682 \\
\hline Gender effect & 264 & 1.00 & 5.00 & 3.8611 & .90421 \\
\hline Age effect & 264 & 2.67 & 4.33 & 4.0922 & .48211 \\
\hline Conservative treatment & 264 & 1.00 & 5.00 & 3.9520 & .81981 \\
\hline Intensity of pain & 264 & 1.00 & 5.00 & 3.4962 & .86877 \\
\hline Working status & 264 & 2.33 & 4.33 & 3.9318 & .78552 \\
\hline Decision on spine surgery & 264 & 2.00 & 5.00 & & .75436 \\
\hline Valid N (list wise) & 264 & & & \\
\hline
\end{tabular}

value of 4.0972 and responses on working status have the lowest mean value of 3.4962 .

Correlation matrix is given in Table 2 has depicted that there is significant positive relationship between all independent variables (previous experience, emotional \& social state, information \& counselling, socioeconomic status, severity of disability, physical health, gender role, age effect, conservative treatment, and intensity of pain) and dependent variable (decision for spine surgery) except working status has an insignificant effect on spine surgery decision $(r=0.1$, $\mathrm{p}>0.05)$. The Cronbach alpha value is given in Table 2 ranges from 0.7 to 0.9 indicating that the instrument is reliable.

Table 2: Correlation Matrix and Cronbach Alpha Values.

\begin{tabular}{|c|c|c|c|c|c|c|c|c|c|c|c|c|}
\hline & 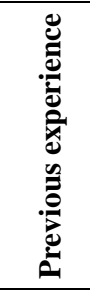 & 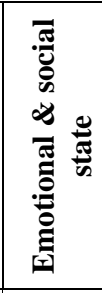 & 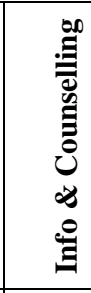 & 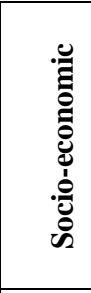 & 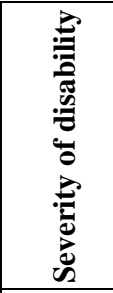 & 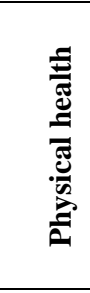 & 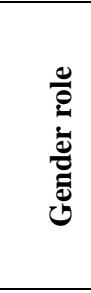 & 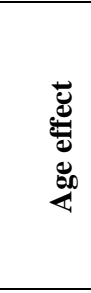 & 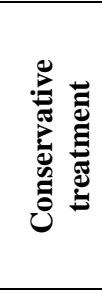 & 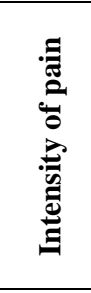 & 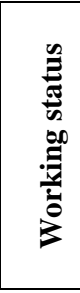 & 苋 \\
\hline Previous experience & 1 & & & & & & & & & & & \\
\hline Emotional \& social state & $.770^{* *}$ & 1 & & . & & & & & & & & \\
\hline Information \& counselling & $.567^{* *}$ & $.637^{* *}$ & 1 & & & & & & & & & \\
\hline Socioeconomic status & $.588^{* * *}$ & $.754^{* * *}$ & $.473^{* *}$ & 1 & & & & & & & & \\
\hline Severity of disability & $.588^{* *}$ & $.704^{* *}$ & $.552^{* *}$ & $.662^{* *}$ & 1 & & & & & & & \\
\hline Physical health & $.632^{* *}$ & $.742^{* *}$ & $.557^{* *}$ & $.661^{* *}$ & $.739^{* *}$ & 1 & & & & & & \\
\hline Gender role & $.389^{* *}$ & $.462^{* *}$ & $.332^{* *}$ & $.414^{* *}$ & $.365^{* *}$ & $.389^{* *}$ & 1 & & & & & \\
\hline Age effect & $.620^{* *}$ & $.627^{* *}$ & $.392^{* * *}$ & $.558^{* *}$ & $.611^{* *}$ & $.633^{* *}$ & $.332^{* *}$ & 1 & & & & \\
\hline Conservative treatment & $.352^{* *}$ & $.382^{* *}$ & $.365^{* *}$ & $.313^{* *}$ & $.450^{* *}$ & $.445^{* *}$ & $.257^{* *}$ & $.366^{* *}$ & 1 & & & \\
\hline Intensity of pain & $.492^{* *}$ & $.529^{* *}$ & $.429^{* *}$ & $.489^{* *}$ & $.461^{* *}$ & $.497^{* * *}$ & $.302^{* * *}$ & $.395^{* *}$ & $.347^{* *}$ & 1 & & \\
\hline Working status & .043 & -.003 & .011 & -.020 & .067 & -.026 & .058 & .030 & $.128^{*}$ & .113 & 1 & \\
\hline Decision & $.486^{* *}$ & $.629^{* *}$ & $.453^{* *}$ & $.544^{* *}$ & $.766^{* *}$ & $.624^{* * *}$ & $.357^{* *}$ & $.490^{* *}$ & $.467^{* *}$ & $.741^{* *}$ & .100 & 1 \\
\hline Cronbach alpha value & .729 & .672 & .871 & .811 & .789 & .820 & .901 & .845 & .748 & .890 & .877 & .833 \\
\hline
\end{tabular}


Factors Affecting Decision Making Process on Spine Surgery: Patients' Perspective

Regression assumptions were satisfied before regression analysis. The results of regression in Table 3 shows that R-Square is 0.806 showing that $80 \%$ variation in dependent variable, i.e., decision on spine surgery is explained by the independent variables of the study.The value of F-statistic is 95.263 and significant $(\mathrm{p}=0.00)$ showing that the model was fit.

Regression analysis revealed that the value of beta coefficient $\beta 1$ is $-0.156(\mathrm{p}=0.001<0.05)$ indicating there is a significant negative relationship between previous bad experiences and decision for spine surgery. If one unit of previous bad experiences increases, it will lead to 0.156 or $15.6 \%$ decrease in decision for the choice of spine surgery.In addition, the results indicated that there is a significant positive influence of emotional and social state $(\beta=$ 0.193, $\mathrm{p}=0.002)$, information \&counselling $(\beta=$ $0.097, \mathrm{p}=0.011)$, socioeconomic status $(\beta=0.131$, $\mathrm{p}=0.004)$, severity of disability $(\beta=0.602, \mathrm{p}=$ $0.000)$, ineffective conservative treatment $(\beta 9=0.082$, $\mathrm{p}=0.013)$ and intensity of pain $(\beta=0.527, \mathrm{p}=0.000)$ on decision for spine surgery in patients. The independent variables, physical health, gender role and age effect were found to have an insignificant effect on dependent variable, i.e., decision on spine surgery $(\mathrm{p}>$ $0.05)$.

\section{DISCUSSION}

The study aimed to identify the factors that influence the decision of patients regarding spine surgery from the patients' perspective. The results found that there is a significant negative relationship between previous bad experiences and decision for spine surgery consistent with results of Andersen. ${ }^{3}$ Another study reported that previous spine surgery of patients decreased their satisfaction with spine surgery. ${ }^{8}$ It is possible that patients having previous spinal surgery to create a perception in their mind that previous surgery may have created the present symptoms. ${ }^{9}$ Results reported that a significant positive influence of emotional and social state on decision for spine surgery in patients consistent with a study claiming that negative feelings from long-lasting symptoms and pain in patients lead to decision on the spine surgery. ${ }^{2}$ Further, a study reported that low social function also leads to choice on spine surgery in patients. ${ }^{4}$

The significant positive relationship of information \& counselling was found on decision for surgery consistent with results of Andersen. ${ }^{3}$ Another study also reported high satisfaction score for patients that were referred to surgeon for consultation and they recommended them a spine surgery. ${ }^{10}$ The positive significant impact of socioeconomic status on the decision for spine surgery was found. It is a unique contribution of the present study as socioeconomic status was not previously taken into account. The country is marked by poverty and low capita per income so this variable was very important in the context. The study results found that severity of disability, ineffective conservative treatment and intensity of pain has a significant positive effect on the decision for spine surgery. These results are consistent with previous studies reported that level of disability associated with restricted life activities, failure of conservative treatment and intense pain affecting mobility, quality of life especially when lower back and limbs are affected lead to spine surgery decision., 
The independent variables physical health, gender role, age and working status were found to have an insignificant effect on dependent variable i.e. decision on spine surgery contrary to previous studies results reported that women less likely opt for surgery because of her caregiver gender role. ${ }^{9}$

\section{CONCLUSION}

From this study, we concluded that there are various factors from the patients' perspective that can influence the decision of patients regarding spine surgery. The most influential factors associated with decision of patients on spine surgery include patients' previous bad experience, emotional \& social state, information \& counselling, socioeconomic status, severity of disability, ineffectiveness of previous conservative treatment and intensity of pain.

\section{REFERENCES}

1. Sollmann N, Morandell C, Albers L, Behr M, Preuss A, Dinkel A, Meyer B, Krieg SM. Association of decisionmaking in spinal surgery with specialty and emotional involvement- the indications in spinal surgery (INDIANA) survey. Acta Neurochirurgica. 2018; 160 (3): 425-438.

2. Lam WW, Loke AY. Factors and concerns of patients that influence the decision for spinal surgery and implications for practice: a review of literature. Int $\mathbf{J}$ Orthop Trauma Nurs. 2017; 1 (25): 11-18.
3. Andersen SB, Birkelund R, Andersen M $\varnothing$, Carreon LY, Coulter A, Steffensen KD. Factors affecting patient decision-making on surgery for lumbar disc herniation. Spine. 2019; 44 (2): 143-149.

4. Kim HJ, Park JY, Kang KT, Chang BS, Lee CK, Yeom JS. Factors influencing the surgical decision for the treatment of degenerative lumbar stenosis in a preference-based shared decision-making process. Eur J Spine, 2015; 24 (2): 339-347.

5. Kløjgaard ME, Manniche C, Pedersen LB, Bech M, Søgaard R. Patient preferences for treatment of low back pain - a discrete choice experiment. Value in Health, 2014; 17 (4): 390-396.

6. Kurd MF, Lurie JD, Zhao W, Tosteson T, Hilibrand AS, Rihn J, Albert TJ, Weinstein JN. Predictors of treatment choice in lumbar spinal stenosis: a SPORT study. Spine, 2012; 37 (19): 1702-1707.

7. Hair JF, Black WC, Babin BJ, Anderson RE. Multivariate data analysis. $7^{\text {th }}$ ed. New Jersey: Prentice Hall, Upper Saddle River; 2010.

8. Sigmundsson FG, Jönsson B, Strömqvist B. Determinants of patient satisfaction after surgery for central spinal stenosis without concomitant spondylolisthesis: a register study of 5100 patients. Euro Spine J. 2017; 26 (2): 473-480.

9. Sure A, Tishelman JC, Moon J, et al. Patient reported satisfaction and its impact on outcomes in spinal surgery: a mini review. Ann Clin Lab Res. 2016; 4 (3): $1-4$.

10. Mazur MD, McEvoy S, Schmidt MH, Bisson EF, Boos N. Spinal Disorders. J Neurosurg. Spine. 2018; 22: 1165.

\section{Additional Information}

Disclosures: Authors report no conflict of interest.

Ethical Review Board Approval: The study was conformed to the ethical review board requirements.

Human Subjects: Consent was obtained by all patients/participants in this study.

Conflicts of Interest:

In compliance with the ICMJE uniform disclosure form, all authors declare the following:

Financial Relationships: All authors have declared that they have no financial relationships at present or within the previous three years with any organizations that might have an interest in the submitted work.

Other Relationships: All authors have declared that there are no other relationships or activities that could appear to have influenced the submitted work.

Address for Correspondence:

Fazal Ghani

Department of Neurosurgery, Khyber Teaching Hospital

Peshawar-Pakistan

Email: doctor_amc03@yahoo.com 
Factors Affecting Decision Making Process on Spine Surgery: Patients' Perspective

AUTHORSHIP AND CONTRIBUTION DECLARATION

\begin{tabular}{|c|c|c|}
\hline Sr.\# & Author's Full Name and Affiliation & Intellectual Contribution to Paper in Terms of: \\
\hline 1. & Fazal Ghani & 1. Study design and methodology. \\
\hline 2. & Fazal Ghani & 2. Paper writing, referencing, data calculations and \\
\hline 3. & Irum Khattak & 3. Data collection and calculations \\
\hline 4. & Fazal Ghani & 4. Analysis of data and interpretation of results etc. \\
\hline 5. & Shabnum Aamir & 5. Literature review and manuscript writing \\
\hline 6. & Irum Khattak & 6. Analysis of data and quality insurer \\
\hline 7. & Farooq Azam & 7. Proof Reading \\
\hline
\end{tabular}

Date of Submission: 18-2-2020

Date of Revision: 14-05-2020

Date of Online Publishing: 30-06-2020

Date of Print: 30-07-2020 